\title{
Dosimetric parameter predicting the deterioration of hepatic function after helical tomotherapy in patients with unresectable locally advanced hepatocellular carcinoma
}

\author{
Seok Hyun Son ${ }^{1}$, Chul Seung Kay ${ }^{1}$, Jin Ho Song ${ }^{1}$, Sea-Won Lee ${ }^{1}$, Byung Ock Choi ${ }^{1}$, Young Nam Kang',
} Jeong Won Jang ${ }^{2}$, Seung Kew Yoon ${ }^{2}$ and Hong Seok Jang ${ }^{1 *}$

\begin{abstract}
Background: The purpose of this study was to identify parameters capable of predicting the deterioration of hepatic function after helical tomotherapy in patients with unresectable locally advanced hepatocellular carcinoma.

Methods: Between March 2006 and February 2012, 72 patients were eligible for this study. All patients received hypofractionated radiotherapy using the TomoTherapy Hi-Art (TomoTherapy, Madison, WI, USA) at Seoul St. Mary's Hospital and Incheon St. Mary's Hospital, the Catholic University of Korea. The radiation dose was a median 50 Gy (range: 40-50 Gy) in 10 fractions to 95\% of the planning target volume. Radiation-induced hepatic toxicity was defined as an increase of at least 2 points in the Child-Pugh (CP) score within 3 months after completion of helical tomotherapy.

Results: An increase of at least 2 points in the CP score occurred in 32 of the 72 patients (44.4\%). Multivariate logistic regression analysis revealed that pretreatment $C P$ class and $V_{15 G y}$ were significant parameters associated with an increase in CP score $(p=0.009$ and $p<0.001$, respectively). The area under receiver operating characteristic curve was 0.863 for $V_{15 G y}(p<0.001)$. For $V_{15 G y}$, with a cutoff value of $43.2 \%$, the accuracy was $0.806(58 / 72)$ with a sensitivity of 0.938 and a specificity of 0.725 .
\end{abstract}

Conclusions: An increase of at least 2 points in the CP score is a radiation dose-limiting factor, and the non-target normal liver receiving a dose more than $15 \mathrm{~Gy}\left(\mathrm{~V}_{15 \mathrm{~Gy}}\right)$ should be $<43.2 \%$ to reduce the risk of the deterioration of hepatic function.

Keywords: Hepatocellular carcinoma (HCC), Helical tomotherapy, Radiation-induced hepatic toxicity (RIHT) Child-Pugh score (CP score), Dosimetric parameter, The deterioration of hepatic function

\section{Background}

Hepatocellular carcinoma (HCC), which is one of the most common malignant carcinomas worldwide, is a fatal disease that might cause death with severe complication if treated improperly [1,2]. Although a surgical resection is considered the treatment of choice, many patients are either inoperable or the tumor is unresectable at the time of diagnosis. In these cases, transarterial

\footnotetext{
*Correspondence: hsjang11@catholic.ac.kr

'Department of Radiation Oncology, College of Medicine, The Catholic University of Korea, Seoul, Korea

Full list of author information is available at the end of the article
}

chemoembolization (TACE), percutaneous ethanol injection (PEI), and radiofrequency ablation (RFA) have been used [3-5]. In contrast, radiotherapy (RT) had not been widely used for the treatment of HCC because of the low dose of radiation tolerable for the entire liver, which was not effective for tumor control [6,7]. However, recently reported studies showed that partial volume irradiation of the liver is feasible and a useful tool for the treatment of HCC within an acceptable range of hepatic toxicity [8-11].

In the use of RT for the treatment of HCC, radiationinduced hepatic toxicity (RIHT) is considered a significant dose-limiting factor because of its potential to cause liver

\section{Biomed Central}


Table 1 Patient's characteristics

\begin{tabular}{|c|c|c|}
\hline Characteristic & $n$ & (\%) \\
\hline \multicolumn{3}{|l|}{ Gender } \\
\hline Male & 54 & 75.0 \\
\hline Female & 18 & 25.0 \\
\hline \multicolumn{3}{|l|}{ Age (year) } \\
\hline Median & 60 & \\
\hline Range & $21-80$ & \\
\hline \multicolumn{3}{|l|}{ ECOG PS } \\
\hline 0 & 23 & 31.9 \\
\hline 1 & 49 & 68.1 \\
\hline \multicolumn{3}{|l|}{ Hepatitis } \\
\hline No & 2 & 2.8 \\
\hline Yes & 70 & 97.2 \\
\hline HBV & 52 & 72.2 \\
\hline $\mathrm{HCV}$ & 6 & 8.3 \\
\hline Others & 12 & 16.7 \\
\hline \multicolumn{3}{|l|}{ Liver cirrhosis } \\
\hline No & 16 & 22.2 \\
\hline Yes & 56 & 77.8 \\
\hline \multicolumn{3}{|l|}{ PVTT } \\
\hline No & 30 & 41.7 \\
\hline Yes & 42 & 58.3 \\
\hline \multicolumn{3}{|l|}{ AFP (IU/mL) } \\
\hline$<400$ & 48 & 66.7 \\
\hline$\geq 400$ & 24 & 33.3 \\
\hline \multicolumn{3}{|l|}{ Child-Pugh class } \\
\hline A & 54 & 75.0 \\
\hline B & 18 & 25.0 \\
\hline \multicolumn{3}{|l|}{ AJCC stage } \\
\hline$\|$ & 12 & 16.7 \\
\hline III & 53 & 73.6 \\
\hline IVA & 7 & 9.7 \\
\hline \multicolumn{3}{|l|}{ Previous treatment } \\
\hline No & 7 & 9.7 \\
\hline Yes & 65 & 90.3 \\
\hline TACE & 63 & 87.5 \\
\hline RFA & 7 & 9.7 \\
\hline PEl & 7 & 9.7 \\
\hline Surgery & 9 & 12.5 \\
\hline \multicolumn{3}{|l|}{ Treatment after RT } \\
\hline No & 31 & 43.1 \\
\hline Yes & 41 & 56.9 \\
\hline TACE & 40 & 55.6 \\
\hline RFA & 2 & 2.8 \\
\hline PEl & 2 & 2.8 \\
\hline Systemic CTx & 3 & 4.2 \\
\hline \multicolumn{3}{|l|}{ Radiation dose } \\
\hline $40 \mathrm{~Gy} / 10 \mathrm{fxs}$ & 6 & 8.3 \\
\hline
\end{tabular}

Table 1 Patient's characteristics (Continued)

\begin{tabular}{lll}
\hline $45 \mathrm{~Gy} / 10 \mathrm{fxs}$ & 10 & 13.9 \\
\hline $50 \mathrm{~Gy} / 10 \mathrm{fxs}$ & 56 & 77.8 \\
\hline
\end{tabular}

Abbreviations: ECOG PS Eastern Cooperative Oncology Group performance status; HBV hepatitis B virus; $H C V$ hepatitis $C$ virus; PVTT portal vein tumor thrombosis; AFP alpha-fetoprotein; AJCC American Joint Committee on Cancer; TACE transcatheter arterial chemoembolization; RFA radiofrequency ablation; $P E I$ percutaneous ethanol injection; $R T$ radiotherapy; $C T x$ chemotherapy; $f x s$ fractions.

failure. This potential underlines the importance of identifying a parameter that can predict, and thus, prevent RIHT. To date, several reports investigating parameters capable of predicting RIHT have been recently published [12-17]; however, these reports are based on clinical data from 3-dimensional conformal radiotherapy (3D-CRT). When compared with 3D-CRT, helical tomotherapy is an advanced technique that can provide a high dose of radiation to the target volume, while reducing the dose to the surrounding normal tissues. But, low to moderate dose of radiation distributed to a much wider region of the normal liver could affect the incidence of RIHT.

Here, we evaluated RIHT reflecting the deterioration of hepatic function in advanced HCC patients treated with helical tomotherapy and identified a parameter capable of predicting RIHT.

\section{Methods \\ Patients}

The inclusion criteria for this study were as follows: 1) unresectable locally advanced HCC, 2) prior treatment by hypofractionated helical tomotherapy with a curative aim, 3) a radiation dose of 40-50 Gy in 10 fractions, 4) 2 or more laboratory studies within 3 months after the completion of helical tomotherapy, 5) 1 or more radiologic studies within 3 months after the completion of helical tomotherapy, and 6) no intrahepatic disease progression within 3 months after the completion of helical tomotherapy.

Between March 2006 and February 2012, 72 patients were eligible for this study. All the patients received hypofractionated RT using the TomoTherapy Hi-Art (TomoTherapy, Madison, WI, USA) at Seoul St. Mary's Hospital and Incheon St. Mary's Hospital, the Catholic University of Korea. The patients' clinical and dosimetric data were retrospectively collected following Institutional Review Board approval. The patients' characteristics are shown in Table 1.

Prior to helical tomotherapy, 65 patients $(90.3 \%)$ were treated with other locoregional treatments such as TACE, RFA, PEI, and surgery. Within 3 months after the completion of helical tomotherapy, TACE was performed in 41 patients (56.9\%) (median: 1 time, average: 1.5 times, range: $1-3$ times). In addition, RFA and PEI were 
performed in 2 patients each $(2.8 \%)$ and systemic chemotherapy was performed in 3 patients $(4.2 \%)$.

\section{Target volume and treatment}

The gross tumor volume (GTV) was defined as the tumor volume that was enhanced in the arterial phase and diluted in the delayed phase of computed tomography (CT) scan. The planning target volume (PTV) was generated by adding $5-15 \mathrm{~mm}$ to the GTV in 52 of the 72 patients, facilitating asymmetric margin expansion to reduce irradiation to the stomach, duodenum, and small intestine. In the remaining 20 of 72 patients, 4-dimensional CT (4D-CT) was performed to generate the internal target volume to compensate for respiratory-induced liver movement because of the installation of 4D-CT in March 2009 at Seoul St. Mary's hospital and in March 2011 at Incheon St. Mary's hospital. Organs at risks such as the total liver, non-target normal liver (NTNL), stomach, duodenum, intestine, kidney, and spinal cord were also contoured for evaluation of the irradiated dose. NTNL volume was the total liver volume minus PTV.

The prescribed radiation dose was a median 50 Gy (range: 40-50 Gy) in 10 fractions to 95\% of the PTV. Prior to the actual beam delivery, megavoltage cone-beam CT was performed at the time of every treatment session. Each patient's set-up and position were corrected with automated image registration, and the anatomical accuracy was always evaluated by a radiation oncologist.

\section{Evaluation of the radiation-induced hepatic toxicity}

RIHT was defined as an increase of at least 2 points in the Child-Pugh (CP) score within 3 months after the completion of helical tomotherapy. CP score, which is calculated on the basis of the serum bilirubin and albumin levels, prothrombin time (PT), and the presence and degree of ascites or encephalopathy, is an assessment of the severity of hepatic function. Thus, an increase in CP score reflects the deterioration of hepatic function [18].

During helical tomotherapy, patients were seen weekly by a physician to evaluate their complaints. After completion of helical tomotherapy, patients were followed-up every 1-2 months. At every visit, physical examinations and blood tests were performed to assess hepatic toxicity. Levels of aspartate transaminase (AST), alanine transaminase (ALT), alkaline phosphatase (ALP), serum albumin, total bilirubin and PT were examined. Ascites and hepatic encephalopathy were also evaluated.

\section{Parameters for predicting RIHT}

The clinical parameters analyzed were gender, age, Eastern Cooperative Oncology Group (ECOG) performance status, pretreatment CP class, American Joint Committee on Cancer (AJCC) stage, pretreatment level of alphafetoprotein (AFP) and the presence or absence of hepatitis, liver cirrhosis, portal vein tumor thrombosis (PVTT) and previous treatments.

The dosimetric parameters analyzed were PTV, mean dose of NTNL, the percentage of NTNL volume receiving $>5$ Gy $\left(\mathrm{V}_{5 \mathrm{~Gy}}\right),>10$ Gy $\left(\mathrm{V}_{10 \mathrm{~Gy}}\right),>15$ Gy $\left(\mathrm{V}_{15 \mathrm{~Gy}}\right),>20 \mathrm{~Gy}\left(\mathrm{~V}_{20 \mathrm{~Gy}}\right)$, $>25$ Gy $\left(\mathrm{V}_{25 \mathrm{~Gy}}\right),>30$ Gy $\left(\mathrm{V}_{30 \mathrm{~Gy}}\right),>35 \mathrm{~Gy}\left(\mathrm{~V}_{35 \mathrm{~Gy}}\right)$, and $>40 \mathrm{~Gy}$ ( $\left.\mathrm{V}_{40 \mathrm{~Gy}}\right)$.

\section{Statistical analyses}

Pearson's chi-square and the independent t-test were used for univariate analysis of the clinical parameters associated with RIHT. Binary logistic regression analysis was used for univariate analysis of dosimetric parameters associated with RIHT. Multivariate analysis was performed using the logistic regression model containing all significant variables according to univariate analysis (selection: stepwise forward). The receiver operating characteristic (ROC) curve was used to estimate the significant dosimetric parameters. All statistical analyses were performed using SPSS ver. 12.0 (SPSS Institute, Chicago, Illinois) and a $p$ value of $<0.05$ was considered significant.

\section{Results}

\section{Clinical and dosimetric parameters associated with an} increase in $\mathrm{CP}$ score

An increase of at least 2 points in the CP score occurred in 32 of 72 patients (44.4\%) within 3 months after completion of helical tomotherapy. Univariate analysis results showing the associations between clinical parameters and the increased the CP score are summarized in Table 2. Age, gender, pretreatment level of AFP, and the presence of hepatitis and/or liver cirrhosis did not contribute to an increase in CP score after helical tomotherapy. In addition, previous treatments and treatments given after completion of helical tomotherapy did not contribute to an increase in CP score $(p=0.374$ and 0.394 , respectively). In contrast, AJCC stage, the presence of PVTT, and pretreatment $\mathrm{CP}$ class were significantly associated with an increase in the $\mathrm{CP}$ score after helical tomotherapy ( $p=0.021,0.037$, and 0.006 , respectively).

Univariate analysis of the associations between the dosimetric parameters and the increase in CP score showed that PTV, mean dose of NTNL, $V_{5 G y}, V_{10 G y}$, $V_{15 \text { Gy }}, V_{20 \text { Gy }}, V_{25 \text { Gy }}, V_{30 \text { Gy }}$ and $V_{35 \text { Gy }}$ were significantly associated with an increase in the CP score (Table 3 ).

Multivariate logistic regression analysis confirmed that pretreatment CP class and $\mathrm{V}_{15 \mathrm{~Gy}}$ were significant parameters associated with an increase in the CP score ( $p=0.009$ and $p<0.001$, respectively). As shown in Figure 1 , the area under the ROC curve (AUC) was 0.863 for $\mathrm{V}_{15 \mathrm{~Gy}}(p<$ 0.001 ), indicating that $\mathrm{V}_{15 \mathrm{~Gy}}$ with a cutoff value of $43.2 \%$ was an appropriate value to predict an increase in the CP score. An increase in the CP score was observed in 2 of 30 patients (6.7\%) 
Table 2 Clinical parameters in patients with or without an increase in Child-Pugh score $\geq \mathbf{2}$

\begin{tabular}{|c|c|c|c|}
\hline & Without $(n=40)$ & With $(n=32)$ & $p$ value \\
\hline Gender & & & 0.584 \\
\hline Male & 31 & 23 & \\
\hline Female & 9 & 9 & \\
\hline Age (years) & & & 0.231 \\
\hline median & 62 & 59 & \\
\hline range & $21-80$ & $41-80$ & \\
\hline ECOG PS & & & 0.910 \\
\hline 0 & 13 & 10 & \\
\hline 1 & 27 & 22 & \\
\hline Hepatitis & & & 0.109 \\
\hline No & 0 & 2 & \\
\hline Yes & 40 & 30 & \\
\hline AFP (IU/mL) & & & 0.094 \\
\hline$<400$ & 30 & 18 & \\
\hline$\geq 400$ & 10 & 14 & \\
\hline LC & & & 0.228 \\
\hline No & 11 & 5 & \\
\hline Yes & 29 & 27 & \\
\hline PVTT & & & ${ }^{*} 0.037$ \\
\hline No & 21 & 9 & \\
\hline Yes & 19 & 23 & \\
\hline CP class & & & ${ }^{*} 0.006$ \\
\hline A & 35 & 19 & \\
\hline B & 5 & 13 & \\
\hline AJCC stage & & & ${ }^{*} 0.021$ \\
\hline$\|$ & 11 & 1 & \\
\hline III & 26 & 27 & \\
\hline IVA & 3 & 4 & \\
\hline Previous treatment & & & 0.374 \\
\hline No & 5 & 2 & \\
\hline Yes & 35 & 30 & \\
\hline Treatment after RT & & & 0.394 \\
\hline No & 19 & 12 & \\
\hline Yes & 21 & 20 & \\
\hline
\end{tabular}

Abbreviations: ECOG PS Eastern Cooperative Oncology Group performance status; AFP alpha-fetoprotein; $L C$ liver cirrhosis; PVTT portal vein tumor thrombosis; CP class Child-Pugh class; AJCC American Joint Committee on Cancer; $R T$ radiotherapy.

*Significant parameters in univariate analysis.

with a $V_{15 G y}$ of $\leq 43.2 \%$ and in 30 of 43 patients $(69.8 \%)$ with a $\mathrm{V}_{15 \mathrm{~Gy}}$ of $>43.2 \%$. For $\mathrm{V}_{15 \mathrm{~Gy}}$, with a cutoff value of $43.2 \%$, the accuracy was $0.806(58 / 72)$ with a sensitivity of 0.938 and a specificity of 0.725 .

Normal liver dose-volume histogram (DVH) reflecting the risk of the deterioration of hepatic function

Close correlations were demonstrated between dosimetric parameters that were shown to be significant in the univariate analysis $\left(\mathrm{V}_{5 \mathrm{~Gy}}\right.$ vs. $\mathrm{V}_{10 \mathrm{~Gy}}, r=0.890, p<0.001$; $\mathrm{V}_{10 \mathrm{~Gy}}$ vs. $\mathrm{V}_{15 \mathrm{~Gy}}, r=0.936, p<0.001 ; \mathrm{V} 1_{5 \mathrm{~Gy}}$ Vs. $\mathrm{V}_{20 \mathrm{~Gy}}$, $r=0.945, p<0.001 ; V_{20 G y}$ vs. $V_{25 G y}, r=0.962, p<0.001$; $\mathrm{V}_{25 \mathrm{~Gy}}$ vs. $\mathrm{V}_{30 \mathrm{~Gy}}, r=0.916, p<0.001 ; \mathrm{V}_{30 \mathrm{~Gy}}$ vs. $\mathrm{V}_{35 \mathrm{~Gy}}$, $r=0.904, p<0.001)$. Although $\mathrm{V}_{15 \mathrm{~Gy}}$ was the only significant dosimetric parameter found in multivariate analysis, other parameters $\left(\mathrm{V}_{5 \text { Gy }}, \mathrm{V}_{10 \mathrm{~Gy}}, \mathrm{~V}_{20 \text { Gy }}, \mathrm{V}_{25 \mathrm{~Gy}}, \mathrm{~V}_{30 \text { Gy }}\right.$ and $V_{35 G y}$ ) that were shown to be statistically significant in univariate analysis also demonstrated similar relationship patterns in their estimated probability curves (Figure 2). Additionally, the area under the ROC curve of each of these parameters was regarded as a good value with statistical significance (Table 3). From these curves, the values indicating a $10 \%, 20 \%$ and $30 \%$ risk of an increase in the $\mathrm{CP}$ score were obtained. These values correspond to the normal liver DVH reflecting the risk of the deterioration of hepatic function. It could provide a treatment planning guideline to reduce the risk of developing the deterioration of hepatic function (Figure 3).

\section{Discussion}

Ablation, chemoembolization, and RT have been used for the treatment of unresectable locally advanced HCC. Because RT alone cannot achieve a complete response in most cases, other locoregional treatments, such as TACE, RFA, and PEI, have been used repeatedly prior to or after RT. After completion of RT, transient elevation of hepatic enzymes such as AST, ALT, and ALP commonly occurs, but, in many cases, these kinds of hepatic toxicities are recovered in a few months [14]. However, if hepatic function deteriorates because of radiation, other necessary treatments cannot be performed in a timely manner. Since no specific treatment for this condition exists except conservative care, it is also important to reduce the development of the deterioration of hepatic function. Thus, it is important to identify a parameter that can predict the deterioration of hepatic function and to develop a plan for RT using the parameter and its values.

The relationship between the radiation dose to liver volume and the incidence of hepatic toxicities has been studied previously [12-15,17]. Radiation-induced liver disease (RILD) is a traditionally accepted concept of hepatic toxicity [7]. In the past, classic RILD was a serious manifestation of hepatic toxicity caused by irradiation of 30-35 Gy to the entire liver. However, the incidence of classic RILD has been lowered, since partial volume irradiation has become more common. Other authors have reported the parameters predicting the non-classic RILD or the elevation of hepatic enzymes $\geq$ grade 2 or 3 according to Radiation Therapy Oncology Group toxicity criteria or Common Terminology Criteria for Adverse Events (CTCAE) and their cut-off values to present a guideline for radiation planning $[12,14,15,17]$. 
Table 3 Dosimetric parameters in patients with or without an increase in Child-Pugh score $\geq 2$

\begin{tabular}{|c|c|c|c|c|c|}
\hline \multirow[t]{2}{*}{ Parameters } & \multirow{2}{*}{$\begin{array}{l}\text { Without } \\
(n=40)\end{array}$} & \multirow{2}{*}{$\begin{array}{c}\text { With } \\
(n=32)\end{array}$} & \multirow[t]{2}{*}{$p$ value $(95 \% \mathrm{Cl})$} & \multicolumn{2}{|c|}{ ROC curve } \\
\hline & & & & AUC & $p$ value \\
\hline PTV $\left(\mathrm{cm}^{3}\right)$ & $103.8 \pm 102.8$ & $227.1 \pm 193.5$ & $0.004(1.002-1.011)$ & 0.741 & $<0.001$ \\
\hline Mean dose of NTNL (Gy) & $14.9 \pm 4.1$ & $20.2 \pm 3.2$ & $<0.001(1.209-1.708)$ & 0.839 & $<0.001$ \\
\hline$\overline{V_{5 G y}}$ & $76.6 \pm 17.5$ & $91.2 \pm 7.6$ & $0.001(1.040-1.153)$ & 0.765 & $<0.001$ \\
\hline $\mathrm{V}_{10 \mathrm{~Gy}}$ & $57.1 \pm 19.1$ & $79.2 \pm 10.7$ & $<0.001(1.048-1.140)$ & 0.830 & $<0.001$ \\
\hline${ }^{*} \bigvee_{15 G y}$ & $39.2 \pm 14.8$ & $61.3 \pm 11.9$ & $<0.001(1.064-1.180)$ & 0.863 & $<0.001$ \\
\hline$V_{20 G y}$ & $27.1 \pm 11.0$ & $44.0 \pm 11.8$ & $<0.001$ (1.069-1.199) & 0.852 & $<0.001$ \\
\hline$V_{25 G y}$ & $19.4 \pm 8.6$ & $30.5 \pm 10.1$ & $<0.001(1.062-1.204)$ & 0.804 & $<0.001$ \\
\hline $\mathrm{V}_{30 \mathrm{~Gy}}$ & $14.8 \pm 7.6$ & $21.6 \pm 8.3$ & $0.002(1.040-1.187)$ & 0.738 & 0.001 \\
\hline$\overline{V_{35 G y}}$ & $10.5 \pm 6.2$ & $15.4 \pm 7.1$ & $0.006(1.033-1.205)$ & 0.706 & 0.003 \\
\hline $\mathrm{V}_{40 \mathrm{~Gy}}$ & $7.2 \pm 5.1$ & $9.9 \pm 5.1$ & $0.053(0.999-1.190)$ & - & - \\
\hline
\end{tabular}

Abbreviations: Cl confidence interval; ROC receiver operating characteristic; AUC area under curve; PTV planning target volume; NTNL non-target normal liver. *Significant parameter on multivariate logistic regression analysis.

Our study differs from previous studies in 3 aspects. First, the presence or absence of an increase of at least 2 points in the CP score as an end-point of RIHT was used for analysis. A few authors have analyzed the elevation of hepatic enzymes (AST, ALT and ALP) as end points to find significant parameters that predict hepatic toxicities [12-15,17]. Kim et al. showed that the elevation of hepatic enzymes was transient and recovered within a median of 2 months after the completion of RT [14]. However, Furuse et al. showed that hypoalbuminemia, hyperbilirubinemia and ascites were important adverse hepatic events that occur after the application of RT to treat advanced HCC, and these events seriously affected survival [19]. An albumin, bilirubin and ascites were used to

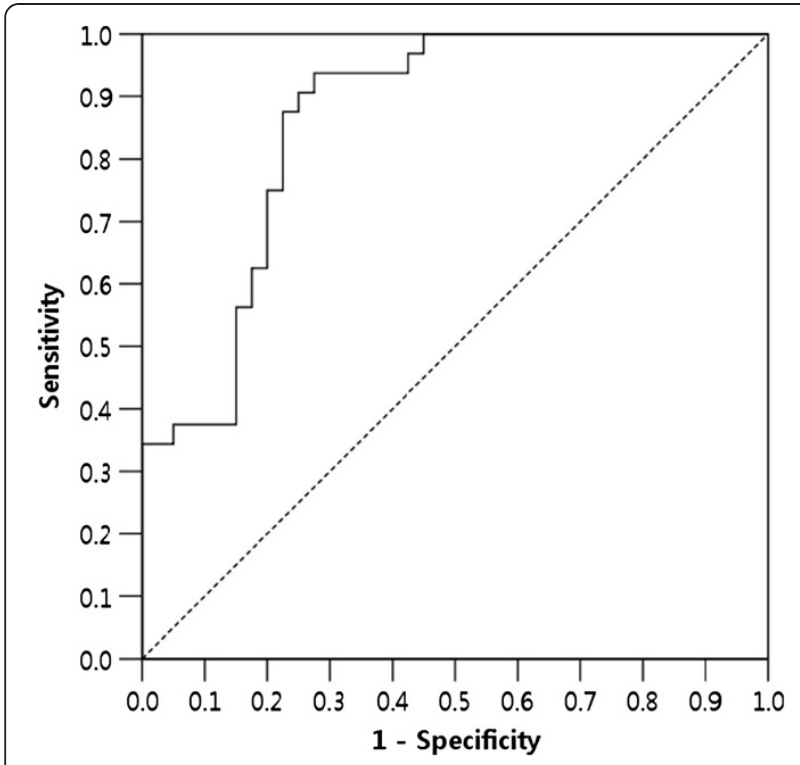

Figure 1 Receiver operating characteristic curve for $V_{15 G y}$. calculate the CP score. In our previous study, the progression of CP class was analyzed as a useful radiation doselimiting factor predicting the deterioration of hepatic function, whereas the elevation of hepatic enzymes according to the CTCAE scale was inappropriate as a useful end point [20]. Liaw et al. also used an increase of at least 2 points in the CP score to evaluate the deterioration of hepatic function in patients who were treated with lamivudine [18]. Therefore, the CP score is appropriate for the assessment of hepatic function, and an increase of at least 2 points in the CP score should be considered the dose-limiting factor.

Another difference between our study and previous studies is that only patients treated with helical tomotherapy were included in the present study. Previous studies regarding the dosimetric parameters predicting hepatic toxicity were based on the data from 3D-CRT. The planning and delivery method of helical tomotherapy is different from that of 3D-CRT. Because helical tomotherapy is delivered continuously from all angles around the patient via a ring gantry, in which the linear accelerator is mounted, a low to moderate radiation dose is delivered to a much wider region of liver. Because of this characteristic, the parameter and its cut-off value could be different between 3D-CRT and helical tomotherapy. According to Kim et al., $\mathrm{V}_{30}$ was demonstrated as a significant parameter in patients treated with conventional fractionated RT [14], and according to Liang et al., $\mathrm{V}_{20}$ was a significant parameter in patients treated with hypofractionated RT (4-6 Gy per fraction) [16]. In our study, a significant parameter is $\mathrm{V}_{15 \mathrm{~Gy}}$, which is a parameter that corresponds to lower doses than those of above studies. The cut-off value of $43.2 \%$ for $\mathrm{V}_{15 \mathrm{~Gy}}$ in our study is lower than that in the above studies $\left(60 \%\right.$ for $V_{30}$ in the study of Kim et al. and $48.5 \%$ for $V_{20}$ in the study of Ling et al.). This result is probably because of the characteristic planning and delivery method of helical tomotherapy and indicates that, to reduce the 


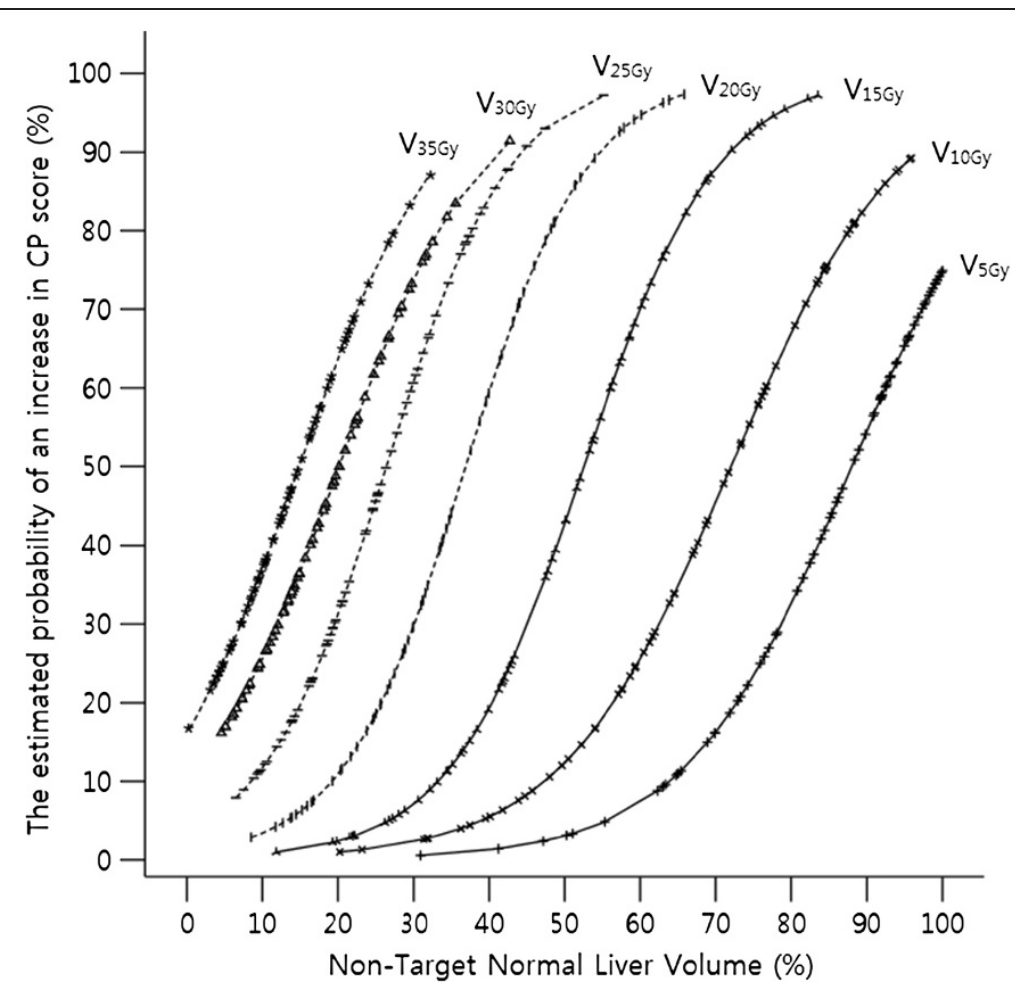

Figure 2 The estimated probability of an increase in CP score for $V_{5 G y}, V_{10 G y}, V_{15 G y}, V_{20 G y}, V_{25 G y}, V_{30 G y}$, and $V_{35 G y}$.

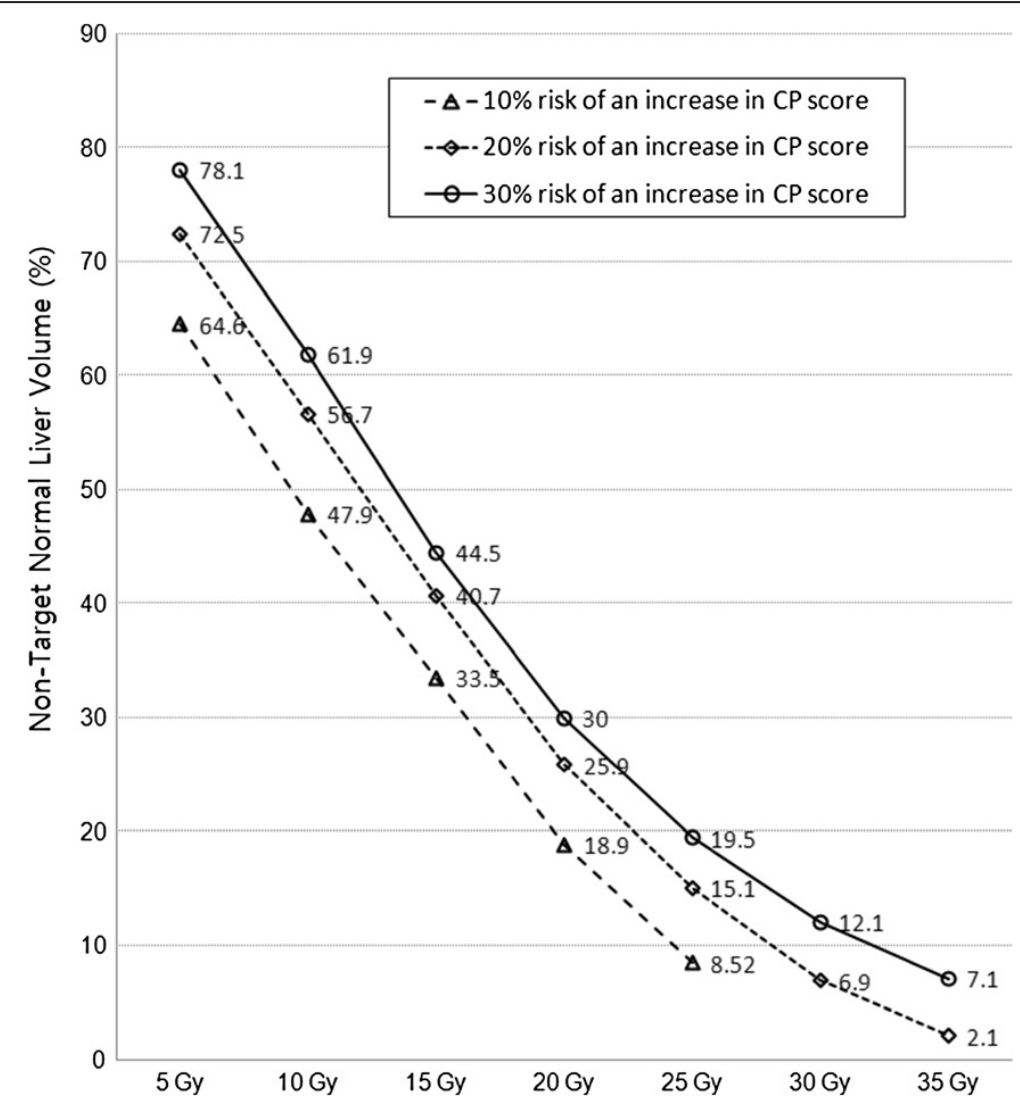

Figure 3 The normal liver dose-volume histogram indicating a 10\%, 20\%, and $30 \%$ risk of an increase in CP score. 
risk of the deterioration of hepatic function, a wider region of normal liver should be preserved from a low to moderate dose of radiation.

The third differences between our study and previous studies is that $\mathrm{V}_{15 \mathrm{~Gy}}$ was confirmed the only significant dosimetric parameter in multivariate analysis. However, because of the significant correlations between dosimetric parameters shown in univariate analysis, consideration of the values of these parameters could be helpful in the treatment planning phase. Based on the estimated probability curves of $\mathrm{V}_{5 G \mathrm{y}}, \mathrm{V}_{10 \mathrm{~Gy}}, \mathrm{~V}_{15 G \mathrm{G}}, \mathrm{V}_{20 \mathrm{~Gy}}, \mathrm{~V}_{25 \mathrm{~Gy}}$, $V_{30 G y}$, and $V_{35 G y}$, which were statistically significant in univariate logistic and ROC curve analyses, we presented the normal liver DVH indicating a $10 \%, 20 \%$, and $30 \%$ risk of the deterioration of hepatic function (Figure 3). This curve could be used as a reference tolerance curve to evaluate treatment plans.

In conclusion, an increase of at least 2 points in the $\mathrm{CP}$ score is a radiation dose-limiting factor, and the nontarget normal liver receiving a dose more than $15 \mathrm{~Gy}$ $\left(\mathrm{V}_{15 \mathrm{~Gy}}\right)$ should be $<43.2 \%$ to reduce the risk of the deterioration of hepatic function. Moreover, the proposed normal liver DVH could be useful as a reference curve to evaluate the dose to the liver.

\section{Abbreviations \\ CP score: Child-Pugh score; HCC: Hepatocellular carcinoma; RIHT: Radiation- induced hepatic toxicity; TACE: Transarterial chemoembolization; PEI: Percutaneous ethanol injection; RFA: Radiofrequency ablation; RT: Radiotherapy; 3D-CRT: 3-dimensional conformal radiotherapy; GTV: Gross tumor volume; PTV: Planning target volume; NTNL: Non-target normal liver; PT: Prothrombin time; AST: Aspartate transaminase; ALT: Alanine transaminase; ALP: Alkaline phosphatase; ECOG: Eastern Cooperative Oncology Group; AJCC: American Joint Committee on Cancer; AFP: Alpha- fetoprotein; PVIT: Portal vein tumor thrombosis; ROC: Receiver operating characteristic; DVH: Dose-volume histogram; RILD: Radiation-induced liver disease; CTCAE: Common Terminology Criteria for Adverse Events; LC: Liver cirrhosis; CTx: Chemotherapy; fxs: Fractions; Cl: Confidence interval; AUC: Area under curve.}

\section{Competing interests}

The authors declare that they have no competing interests.

\section{Authors' contributions}

SHS, JHS, SWL, BOC and HSJ collected clinical data and interpreted the results. SHS and YNK collected and evaluated dosimetric data. SHS, CSK, HSJ, JWJ, and SKY took care of patients. SHS, CSK, JWJ, SKY and HSJ were involved in study design. SHS performed statistical analysis and drafted the manuscript. All the authors have read and approved the final draft.

\section{Author details \\ 'Department of Radiation Oncology, College of Medicine, The Catholic University of Korea, Seoul, Korea. ${ }^{2}$ Department of Internal Medicine, College of Medicine, The Catholic University of Korea, Seoul, Korea.}

Received: 1 July 2012 Accepted: 5 January 2013

Published: 9 January 2013

\section{References}

1. Okuda K, Ohtsuki T, Obata H, Tomimatsu M, Okazaki N, Hasegawa H, Nakajima Y, Ohnishi K: Natural history of hepatocellular carcinoma and prognosis in relation to treatment. Study of 850 patients. Cancer 1985, 56(4):918-928.

2. Parkin DM, Bray F, Ferlay J, Pisani P: Estimating the world cancer burden: Globocan 2000. Int J Cancer 2001, 94(2):153-156.

3. Camma C, Schepis F, Orlando A, Albanese M, Shahied L, Trevisani F, Andreone P, Craxi A, Cottone M: Transarterial chemoembolization for unresectable hepatocellular carcinoma: meta-analysis of randomized controlled trials. Radiology 2002, 224(1):47-54.

4. Lencioni R, Pinto F, Armillotta N, Bassi AM, Moretti M, Di Giulio M, Marchi S, Uliana M, Della Capanna S, Lencioni M, et al: Long-term results of percutaneous ethanol injection therapy for hepatocellular carcinoma in cirrhosis: a European experience. Eur Radiol 1997, 7(4):514-519.

5. Solbiati L, Livraghi T, Goldberg SN, lerace T, Meloni F, Dellanoce M, Cova L, Halpern EF, Gazelle GS: Percutaneous radio-frequency ablation of hepatic metastases from colorectal cancer: long-term results in 117 patients. Radiology 2001, 221(1):159-166.

6. Cochrane AM, Murray-Lyon IM, Brinkley DM, Williams R: Quadruple chemotherapy versus radiotherapy in treatment of primary hepatocellular carcinoma. Cancer 1977, 40(2):609-614.

7. Lawrence TS, Robertson JM, Anscher MS, Jirtle RL, Ensminger WD, Fajardo LF: Hepatic toxicity resulting from cancer treatment. Int I Radiat Oncol Biol Phys 1995, 31(5):1237-1248.

8. Cheng JC, Chuang VP, Cheng SH, Huang AT, Lin YM, Cheng TI, Yang PS, You DL, Jian JJ, Tsai SY, et al: Local radiotherapy with or without transcatheter arterial chemoembolization for patients with unresectable hepatocellular carcinoma. Int J Radiat Oncol Biol Phys 2000, 47(2):435-442.

9. Park W, Lim DH, Paik SW, Koh KC, Choi MS, Park CK, Yoo BC, Lee JE, Kang MK, Park YJ, et al: Local radiotherapy for patients with unresectable hepatocellular carcinoma. Int I Radiat Oncol Biol Phys 2005, 61(4):1143-1150.

10. Robertson JM, McGinn CJ, Walker S, Marx MV, Kessler ML, Ensminger WD, Lawrence TS: A phase I trial of hepatic arterial bromodeoxyuridine and conformal radiation therapy for patients with primary hepatobiliary cancers or colorectal liver metastases. Int J Radiat Oncol Biol Phys 1997, 39(5):1087-1092.

11. Seong J, Keum KC, Han KH, Lee DY, Lee JT, Chon CY, Moon YM, Suh CO, Kim GE: Combined transcatheter arterial chemoembolization and local radiotherapy of unresectable hepatocellular carcinoma. Int I Radiat Oncol Biol Phys 1999, 43(2):393-397.

12. Cheng JC, Wu JK, Huang CM, Liu HS, Huang DY, Cheng SH, Tsai SY, Jian JJ, Lin YM, Cheng TI, et al: Radiation-induced liver disease after threedimensional conformal radiotherapy for patients with hepatocellular carcinoma: dosimetric analysis and implication. Int J Radiat Oncol Biol Phys 2002, 54(1):156-162.

13. Dawson LA, Normolle D, Balter JM, McGinn CJ, Lawrence TS, Ten Haken RK: Analysis of radiation-induced liver disease using the Lyman NTCP model. Int J Radiat Oncol Biol Phys 2002, 53(4):810-821.

14. Kim TH, Kim DY, Park JW, Kim SH, Choi Jl, Kim HB, Lee WJ, Park SJ, Hong EK, Kim CM: Dose-volumetric parameters predicting radiation-induced hepatic toxicity in unresectable hepatocellular carcinoma patients treated with three-dimensional conformal radiotherapy. Int J Radiat Oncol Biol Phys 2007, 67(1):225-231.

15. Lee IJ, Seong J, Shim SJ, Han KH: Radiotherapeutic parameters predictive of liver complications induced by liver tumor radiotherapy. Int J Radiat Oncol Biol Phys 2009, 73(1):154-158.

16. Liang S, Huang X, Zhu X, Zhang W, Cai L, Huang H, Li Y, Chen L, Liu M: Dosimetric predictor identification for radiation-induced liver disease after hypofractionated conformal radiotherapy for primary liver carcinoma patients with Child-Pugh Grade A cirrhosis. Radiother Oncol 2011, 98(2):265-269.

17. Liang $S X$, Zhu XD, Xu ZY, Zhu J, Zhao JD, Lu HJ, Yang YL, Chen L, Wang AY, Fu XL, et al: Radiation-induced liver disease in three-dimensional conformal radiation therapy for primary liver carcinoma: the risk factors and hepatic radiation tolerance. Int I Radiat Oncol Biol Phys 2006, 65(2):426-434.

18. Liaw Y, Sung JJ, Chow WC, Farrell G, Lee C, Yuen H, Tanwandee T, Tao Q, Shue K, Keene ON, et al: Lamivudine for patients with chronic hepatitis B and advanced liver disease. N Engl J Med 2004, 351(15):1521-1531. 
19. Furuse J, Ishii H, Nagase M, Kawashima M, Ogino T, Yoshino M: Adverse hepatic events caused by radiotherapy for advanced hepatocellular carcinoma. J Gastroenterol Hepatol 2005, 20(10):1512-1518.

20. Son SH, Choi BO, Ryu MR, Kang YN, Jang JS, Bae SH, Yoon SK, Choi IB, Kang KM, Jang HS: Stereotactic body radiotherapy for patients with unresectable primary hepatocellular carcinoma: dose-volumetric parameters predicting the hepatic complication. Int I Radiat Oncol Biol Phys 2010, 78(4):1073-1080

doi:10.1186/1748-717X-8-11

Cite this article as: Son et al: Dosimetric parameter predicting the deterioration of hepatic function after helical tomotherapy in patients with unresectable locally advanced hepatocellular carcinoma. Radiation Oncology 2013 8:11

\section{Submit your next manuscript to BioMed Central and take full advantage of:}

- Convenient online submission

- Thorough peer review

- No space constraints or color figure charges

- Immediate publication on acceptance

- Inclusion in PubMed, CAS, Scopus and Google Scholar

- Research which is freely available for redistribution 